\title{
CARIBBEAN EXPERIMENT
}

According to the old saying, prevention is better than cure, and this is taken as a guiding principle by National Red Cross Societies in the Caribbean area as well as by the League of Red Cross Societies. This was clear when representatives of those National Societies met in Port of Spain, Trinidad and Tobago, from 22 to 30 June 1968, for a seminar on pre-disaster planning, organized jointly by the Trinidad and Tobago Red Cross and the League.

Why the Caribbean? Because every year the region is ravaged by hurricanes, cyclones and other natural disasters bringing ruin in their wake across vast areas of the land, causing many victims and considerable damage. The Trinidad and Tobago Red Cross, which experienced the tragedy of hurricane "Flora " which ravaged Tobago a few years ago, had for a long time considered it necessary to hold a seminar to study precautionary measures and the development of co-operation among National Societies of the region, particularly to cope with disaster. The proposal was approved at the VIIIth Inter-American Red Cross Conference at Bogota in November 1966, and again a year later at the League Board of Governors' meeting.

The purpose of the seminar was to consider existing pre-disaster plans and the possibility of developing inter-Society aid in the event of disaster. It had been preceded by a fact-finding mission undertaken by two League delegates, one of whom was made available by the American Red Cross (Mr. E. V. Bighinatti), which visited all the Red Cross Societies of the region to enquire into each country's preparedness. Its findings were communicated to 


\section{IN THE ReD Cross World}

the seminar which was attended by delegates from the National Societies of Barbados, the Dominican Republic, France, Great Britain, Guyana, Haiti, Jamaica, Mexico, the Netherlands, the United States and Trinidad and Tobago, as well as by representatives from a dozen national and international organizations which had been invited to participate.

One of the seminar's most important and widely approved actions was the adoption of constructive recommendations. These were submitted to the League and should permit Caribbean National Societies to broaden the scope of their disaster relief when immediate action is called for. What was the gist of these recommendations?

The drawing up of disaster relief plans on a national scale, it was agreed, was imperative and governments should call attention to the special responsibilities of Red Cross Societies for disaster relief. In addition, the seminar urged that an approach be made to the United Nations Secretary General for part of the allocation from the Working Fund provided for by the U.N. General Assembly's resolution No. 2034 (XX) to be earmarked for pre-disaster relief planning and technical seminars connected with the preparation and organization of disaster relief programmes.

Other recommendations referred to the need for each National Society to maintain an up-to-date register of its trained voluntary workers, and to be immediately informed by the government authorities of any disaster or threat of disaster on their territory.

No doubt the most important of the resolutions adopted was the following:

This seminar recommends the establishment of a Caribbean Red Cross Centre for preparedness and disaster relief to enable each National Red Cross Society, chapter or branch, in the Caribbean to derive in a more rapid and efficient manner the complementary assistance necessary for disaster relief preparedness and the discharge of their mission in the event of major disaster.

In addition, the League was requested to agree to the holding of another seminar in the Caribbean for the purpose of continuing 


\section{IN THE RED Cross WorLd}

preparations for relief in the event of disaster in the region. This meeting might be held in the second quarter of 1970 and participants gratefully accepted the offer of the Haiti Red Cross to organize it at Port-au-Prince.

This new experiment in the Caribbean will undoubtedly have very important consequences for the future of the Red Cross in that part of the world. National Societies in the region are fully aware of the need to intensify the training of technical personnel not only to forecast disaster and warn the population, but also to give immediate assistance after the event. This is the more important as the Caribbean is a disaster prone region where constant preparedness is essential.

José GÓMEZ RUIZ

Head of Latin American and

Caribbean Service of the

League of Red Cross Societies 